\title{
Ricotia carnosula'nın saksı bitkisi olarak kullanımında bitki yoğunluğunun peyzaj performansına Etkisi
}

\section{The effect of plant density on landscape performance of Ricotia carnosula that used as a potted plant}

\author{
Selma KÖSA
}

Akdeniz Üniversitesi, Mimarlık Fakültesi, Peyzaj Mimarlığı Bölümü, Antalya, Türkiye

\section{Eser Bilgisi / Article Info}

Araştırma makalesi / Research article DOI: 10.17474/artvinofd.593869

Sorumlu yazar / Corresponding author

Selma KÖSA

e-mail: selmakosa@akdeniz.edu.tr

Geliş tarihi / Received

18.07.2019

Düzeltme tarihi / Received in revised form

25.10.2019

Kabul Tarihi / Accepted

21.11.2019

Elektronik erişim / Online available

12.12.2019

\section{Anahtar kelimeler:}

Ricotia carnosula

Peyzaj performansı

Saksılı bitki

Bitkisel tasarım

\section{Keywords:}

\section{Ricotia carnosula}

Landscape performance

Potted plant

Planting design

\begin{abstract}
Özet
Peyzaj mimarlığında özellikle ön bahçelerde ve dar alanlarda farklı görsel etkiler yaratmak amacıyla saksılı bitkilerle bitkisel tasarımlar yapılabilmektedir. Saksılı bitki kullanımlarında mevsimlik çiçeklerin kullanımı çoğu zaman, kullanıcılara bakım açısından kolaylık sağlarken aynı zamanda farklı mevsimlerde tür çeşitliliği yaratmada pratik çözümler sunmaktadır. Bu çalışma, Ricotia carnosula türünün saksılı kullanımındaki peyzaj performansına bitki yoğunluğunun etkisini belirlemek amacıyla 2018 yılında Antalya merkezde, açık alanda, Mart-Mayıs ayları (8 hafta) arasında gerçekleştirilmiştir. Çalışmada, sadece toprak ortamının doldurulduğu çapı $20 \mathrm{~cm}$ olan 1.5 litrelik plastik saksılardaki 3 farklı bitki yoğunluğunun (saksı başına 1, 3, 5 bitki) peyzaj performansına olan etkisi, her hafta yapılan bitki büyüme özelliklerinin ölçülmesi ve görsel kalitenin puanlanması ile belirlenmiştir. Çalışma sonucunda, görsel kalitenin ve bitki büyüme özelliklerinin farklı bitki yoğunluklarına göre farklılıklar gösterdiği belirlenmiş ve en iyi peyzaj performansının 3 bitkili saksılarda olduğu tespit edilmiştir. Bu çalışma, $R$. carnosula türünün saksılı kullanımında yaklaşık 8 hafta boyunca çiçeklenme göstererek etkinliğini sürdürebildiğini ve bitkisel tasarımda saksılı bitki olarak kullanımının mümkün olabildiğini ortaya koymuştur.
\end{abstract}

\begin{abstract}
In landscape architecture, especially in front gardens and narrow spaces, planting designs can be made with potted plants to create different visual effects. In potted plant uses, the use of seasonal flowers often provides convenience to the user in terms of care, but also provides practical solutions for creating species diversity in different seasons. The aim of this study was to determine the effect of plant density on landscape performance of potted use of Ricotia carnosula in 2018 in the open area of Antalya in March-May ( 8 weeks). In this study, the effect of 3 different plant densities (1, 3, 5 plants per pot) on landscape performance in 1.5 liter plastic pots with a diameter of $20 \mathrm{~cm}$, which is filled only with soil medium, was determined by measuring the plant growth characteristics and scoring the visual quality each week. As a result of the study, it was determined that visual quality and plant growth characteristics showed differences according to different plant densities and the best landscape performance was determined in pots (3 plants per pot). This study showed that $R$. carnosula was able to maintain its efficacy in flowering for about 8 weeks and could be used as a potted plant in planting design.
\end{abstract}

\section{GiRiş}

Süs bitkilerinin, bitkisel tasarımda en iyi görsel kalite ve bitki büyüme özelliklerini gösterdiği kullanım şekillerinin tespiti için yapılan peyzaj performansını belirleme çalışmaları, yapılan tasarımın başarısına ve sürdürülebilirliğine önemli katkılar sağlamaktadır. Mevsimlik çiçeklerin peyzaj performanslarının belirlemesine yönelik yapılan çalışmalar incelendiğinde, bu çalışmaların türlerin kullanım şekillerine ve özelliklerine göre farklı faktörleri dikkate aldığı; sadece büyüme özelliklerinin ölçülmesi, sadece görsel kalitenin belirlenmesi veya hem bitki büyüme özelliklerinin ölçülmesi hem de görsel kalitenin belirlenmesi ile gerçekleştirilebildiği görülmektedir. Örneğin, Wilson ve Knox (2009) 10 adet Pennisetum çeşidinin peyzaj performansın; görsel kalite, çiçeklenme ve bitki büyümesini değerlendirerek belirlemişlerdir. Contreras ve ark. (2013) ise Pennisetum hibritlerinin saksıdaki ve arazideki peyzaj performanslarını büyüme formlarının ve renklerinin değerlendirilmesine göre belirlemişlerdir. Coker ve ark. (2005), Coleus çeşitlerinin, çiçeklenme, dayanıklılık, kuvvet, tek olma ve böcek ve hastalık direnci kriterlerine dayalı peyzaj performansını belirlerken, Freyre ve ark. (2012) ise Ruellia simplex'in peyzaj performansını aylık olarak çiçeklenme ve meyve 
özelliklerini ölçerek ortaya koymuşlardır. Owings ve ark. (2010) ise, Liriope çeşitlerinin ve Ophiopogon japonicus'un mevsimsel peyzaj performansını, görsel kalite, bitki boyu, bitki genişliği, çiçeklenme özellikleri ve hastalık durumunu ölçerek belirlemişlerdir. Niu ve ark. (2007), tuzlu suyun 10 tane otsu bitki türünün performansına etkisini bitki büyümesi ve görsel kaliteyi belirleyerek tespit etmişlerdir. Mevsimlik çiçeklerin özellikle bitki parterlerindeki kullanımlarında en iyi bitki büyüme özelliklerini gösterdiği dikim aralıklarını belirlemeye yönelik çalışmalar (Tyagi ve ark. 2006, Chauhan ve ark. 2014, ShiZhen ve ark. 2011, Bhati ve Chitkara 1987, Rao ve ark. 1992, Dixit ve Keskar 1994, Rani ve Kumar 1999, Barman ve Pal 1999, Mohanty ve ark. 1997, Khanna ve ark. 1986, Jhon ve ark. 1984, Gowda ve Jayanthi 1986, Belorkar ve ark. 1992, Jhon ve ark. 1991, Mishra 1998, Kobza 1993, Vijayakumar ve ark. 1988) da göstermektedir ki en iyi büyüme özelliklerinin elde edildiği dikim aralıkları türden türe değişmektedir. Böylece türler farklı dikim aralıklarında farklı peyzaj performansına sahip olabilmektedir.

Son yıllarda bitkisel peyzaj tasarımında doğal türlerin kullanımı, bakım giderlerinin azaltılması ve sürdürülebilirliğin en önemli unsuru olarak görülmekte ve bu yaklaşım gittikçe yaygınlaşmaktadır (Heywood 2003, Scheiber ve ark. 2008, Karaguzel ve Girmen 2009, Brzuszek ve ark. 2010, Kösa ve Karagüzel 2012). Antalya doğal florası, Antalya koşullarında ve Antalya'yanın sahip olduğu ekolojik koşullara benzer bölgelerdeki peyzaj tasarımlarında mevsimlik çiçek olarak kullanılma potansiyeli olan çok sayıda otsu bitki tür varlığına sahiptir. Arı ve ark. (2010) Antalya koşullarında doğal olarak bulunan otsu türlerin peyzajda kullanımına yönelik mevcut durumu inceledikleri çalışma sonucunda, Pancratium maritimum (Kum zambağı), Anemone coronaria (Manisa lalesi), Gladiolus sp. (Glayöl), Cyclamen sp. (Sıklamen) ve Silene armeria (Silene) gibi otsu türlerin peyzaj mimarları ve fidanlık işletmeleri tarafından kültüre alınma çalışmalarının yapıldığını tespit etmişlerdir. Bu çalışma sonucu da göstermektedir ki Antalya koşullarında yer örtücü ve mevsimlik çiçek olarak kullanılacak doğal türlere ihtiyaç bulunmaktadır.
Güney Doğu Avrupa, Doğu Akdeniz ve komşu Ortadoğu'da yayılış gösteren Ricotia cinsi; 9 tür ile dünyada (Burtt 1951, Appel ve Al-Shehbaz 2003, Selvi ve Paksoy 2013), 5 'i endemik olmak üzere 6 tür ile Türkiye'de (Özüdoğru ve ark. 2008) temsil edilmektedir. Bölgesel ölçekte geniş yayılış gösteren endemik $R$. carnosula Boiss. \& Heldr. (Özüdoğru ve ark. 2008) türü, konik olmayan, çizgisel-dikdörtgen şeklinde ve 12 taneye kadar tohum içeren meyvelere ve (10-)11-12 mm boyutlarında taç yapraklara sahip olup Türkiye'de 0-700 m yüksekliklerde kayalık alanlarda (Davis 1985), Akdeniz bölgesinde Muğla, Antalya ve Adana'da doğal olarak bulunan tek yıllık otsu bir türdür. Nikelce zengin, eğimli, kayalık-taşık alanlarda yetişme özelliği göstermektedir. $20-30 \mathrm{~cm}$ boylanan bu tür, Mart-Nisan aylarında açan hafif kokulu, küçük, beyazlila-pembe renkli çiçeklere sahiptir. Tohum ile çok kolay şekilde çoğaltılabilmektedir. Bitkisel peyzaj tasarımlarında etkileyici form ve çiçekleri nedeniyle kışın kullanılabilecek yeni bir mevsimlik tür adayı olarak ( $\mathrm{Ar}$ 2010), kaya bahçesi bitkisi, bordür, parter ve kasa-saksı bitkisi olarak kullanımı uygun bir türdür.

Ricotia türlerinin fidanlıklarda çoğaltılıp yetiştirilmeleri ve peyzaj tasarımlarında kullanımlarına ilişkin çalışmalar ve bilgiler oldukça sınırlıdır. Ricotia cinsi ile literatürde var olan çalışmalar incelendiğinde çalışmaların daha çok, genetik çeşitliliği belirleme (Kossover ve ark. 2009), yaprak ve sap anatomilerinin belirlenmesi (Selvi ve Paksoy 2013), filogeni, sınıflandırma ve biyocoğrafik sonuçlarının belirlenmesi (Özüdoğru ve ark. 2015), populasyon yapılar ve yeni yayılış alanlarının belirlenmesi (Özüdoğru ve ark. 2008), yeniden tanımlanma, koruma durumu ve yayılışın belirlenmesi (Özüdoğru ve ark. 2012) kapsamlarında olduğu dikkat çekmektedir. Ayrıca, Kösa ve Uysal (2016) R. carnosula'nın Antalya'daki farklı rakımlardaki doğal populasyonlarında bazı morfolofik özelliklerini belirlemişlerdir. Arı ve ark. (2014) ise R. carnosula'nın Antalya'da Kemer bölgesinden farklı rakımlardan aldıkları tohumların çimlenme oranlarını ve bitkilerin yaşama durumlarını tespit etmişlerdir.

Mevsimlik çiçekler bitkisel tasarımlarda, bitki parterlerinde geniş alanlarda kullanılmaları yanında, daha küçük ve dar alanlarda saksılar içerisinde kullanılarak farklı düzenlemelere katkı sağlayabilmektedirler. 
Yamamoto (2017), saksılı bitkiler ile kamusal alanların yeşillendirilmesinin, yoğun nüfuslu yerleşim yerlerinde yaşam kalitesini artırdığını bildirmektedir. GuoHua ve ark. (2014), saksılı çiçeklerin insanların günlük yaşamında gittikçe daha fazla önem kazandığından, ekim alanı ve satış hacminin son yıllarda büyük ölçüde artı̆̆ını vurgulamaktadır. Ferrante ve ark. (2015) çiçekli ve yapraklı saksılı bitkilerin kalitesinin esasen, çiçek ve yaprakların şekline, boyutuna, rengine ve dönüşümüne bağlı olan görsel görünüm ile tanımlandığını, saksılı olarak kullanılan süs bitkilerinin kalitesini farklı faktörlere göre değerlendiren çok sayıda bilimsel çalışma yapıldığını ve bu konuda incelediği yayınların \% 36.8'nin görsel kalite faktörünü baz alarak bitki kalitesini belirlediğini bildirmektedir. Saksılı bitkilerde saksıdaki bitki yoğunluğu, bitkilerin büyüme özelliklerini etkileyebilmektedir. Blanusa ve ark. (2009) Petunia hybrida 'Hurrah White' ve Impatiens 'Cajun Violet' çeşitleriyle yaptığı çalışma sonucunda, saksıdaki bitki sayısının ve kombinasyonunun bitkilerin bireysel performansını etkilediğini vurgulamaktadır.

Bu çalışmada, mevsimlik çiçek olarak kullanılma potansiyeli bulunan endemik $R$. carnosula'nın bitkisel tasarımda saksılı bitki olarak kullanımında bitki yoğunluğunun peyzaj performansına etkisinin araştırılması amaçlanmaktadır.

\section{MATERYAL VE YÖNTEM}

Bu çalışmada, Antalya ili Kemer ilçesinde karayolu kenarında doğal olarak yetişmekte olan Dişli Cavlak [Ricotia carnosula (BOISS. ET HELDR.)] doğal populasyonundan alınan tohumların çimlendirilmesi sonucu elde edilen fideler, bitkisel materyal olarak kullanıımıştır. Mayıs ayı sonunda toplanarak laboratuvar koşullarında saklanan tohumlar, Ocak ayı başında viyollerde Perlit+Torf (1:1 hacimsel) karışımına ekilmiş ve cam serada otomatik sisleme altında çimlendirilmiş ve elde edilen $\sim 4,0 \mathrm{~cm}$ uzunluğundaki fideler 8 Mart tarihinde Antalya'da sadece toprak ortamı doldurulmuş çapı $20 \mathrm{~cm}$ olan 3 litrelik saksılara şaşırtılmıştır. Araştırma Antalya merkezde açık alanda gerçekleştirilmiştir. Oluşturulan yetiştirme ortamından deneme öncesi örnekler alınarak analiz ettirilmiş ve ortamların bazı temel fiziksel ve kimyasal özellikleri belirlenmiştir (Çizelge 1).

Çalışmada, saksılardaki bitki yoğunluğunun bitkilerin peyzaj performansına (büyüme özellikleri ve görsel kalitesine) olan etkilerinin belirlenmesi amacıyla, saksılara 1 bitki, 3 bitki ve 5 bitki dikimi gerçekleştirilmiştir. 1 bitkili saksılarda bitki saksıların tam merkezine dikilmiş, 3 bitkil saksılarda bitkiler arasında $8.5 \mathrm{~cm}$ aralık olacak şekilde üçgen dikim modeli ile dikilmiş, 5 bitkili bitkilerde ise 1 . bitki saksının tam merkezinde olacak şekilde diğer 4 bitki ise $x$ ve y ekseni üzerinde ve merkezdeki 1. bitkiden 5 er $\mathrm{cm}$ uzaktaki noktalara $5 \mathrm{er} \mathrm{cm}$ dikim aralıkları olacak şekilde dikilmişlerdir (Şekil 1). Antalya koşullarında açıkta gerçekleştirilen deneme üç yinelemeli tesadüf parselleri deneme desenine göre kurulmuş ve her yinelemede 10 bitki kullanılmıştır. Deneme Mart- Mayıs 2018 döneminde yürütülmüş ve bitkiler ihtiyaç duyuldukça elle sulanmıştır.

Peyzaj performansları, bitki büyüme özelliklerinin ölçülmesi ve Peyzaj Mimarı veya Ziraat Mühendisi olan 3 uzman kişi tarafından görsel kalitenin puanlanması ile belirlenmiştir. Bitki büyüme özelliklerinin ölçülmesine 20 Mart tarihinde başlanmış ve 7 gün aralıklarla bitki boyu, yaprak sayısı, çiçek sayısı, çiçekli sürgün sayısı ve çiçekli sürgün uzunluğu özellikleri ölçülmüş ve 8 Mayıs tarihinde sonlandırılmıştır. Görsel kalitenin puanlaması bitki çiçek tomurcuklarını oluşturmaya başladıktan sonra başlamış ve haftada bir kez olmak üzere yapılmıştır. Görsel kalitenin belirlenmesinde alanı kaplama performansı (form, bitki boyutları) ve çiçeklenme performans belirlenmiştir. Her iki görsel kalite değerlendirme kategorisinde de 1-5 arasında puanlama yapılmıştır. Alanı kaplama performansında $1=(<\% 25)$, alanı kaplama zayıf, kabul edilemez ; $2=(\%$ 25-50), alanı kaplama orta, kabul edilebilir; $3=(\% 50)$, alanı kaplama iyi; $4=(\% 75)$, alan kaplama çok iyi, kabul edilebilir peyzaj performansı; 5 $=(\% 100)$, alanı kaplama mükemmel, maksimum peyzaj performansı, esas alınarak değerlendirilmiştir. Çiçeklenme performansında $1=\% 0$, hiç çiçek mevcut değil; 2 = \% 25, çiçeklenme zayıf kabul edilemez; $3=\%$ 50, çiçeklenme orta, kabul edilebilir; $4=\% 75$, çiçeklenme çok iyi, kabul edilebilir peyzaj performansı ve $5=\% 100$, maksimum çiçeklenme, maksimum peyzaj performansı esas alınarak değerlendirilmiştir. Peyzaj performansının 
tespit edilmesinde izlenen yöntemin belirlenmesinde, Niu ve ark. (2007), Owings ve ark. (2010), Wilson ve Knox (2009), Freyre ve ark. (2012) ve Coker ve ark. (2005)'nın çalışmalarından yararlanılmıştır. Ayrıca görsel kalitenin değerlendirilmesini açıklayan Çizelge 2'nin oluşturulmasında Wilson ve Knox (2009)'un çalışmasında yer alan görsel kalite değerlendirme çizelgesinin şablonu kullanılmıştır.

Deneme süresince Antalya'da gerçekleşen aylık ortalama sıcaklık değerleri 2018 yılı Mart, Nisan ve Mayıs aylarında sırasıyla $16.1^{\circ} \mathrm{C}, 19.6^{\circ} \mathrm{C}$ ve $23.3^{\circ} \mathrm{C}$ olarak ölçülmüştür. Aynı dönem içinde minimum sıcaklık değerleri aylara göre sırasıyla $0,1^{\circ} \mathrm{C}, 12,6^{\circ} \mathrm{C}$ ve $15.4^{\circ} \mathrm{C}$ iken, maksimum sıcaklık değerleri ise sırasıyla $23.9^{\circ} \mathrm{C}, 34.6^{\circ} \mathrm{C}$ ve $32.4^{\circ} \mathrm{C}$ olarak ölçülmüştür.

$\mathrm{Bu}$ çalışmada verilerin değerlendirilmesinde Kösa ve Karagüzel(2012)'in çalışmalarında kullandığı yöntemden yararlanılmış, elde edilen verilerden zamana bağlı değişimlerle ilgili olanlar grafikler şeklinde değerlendirilmiş, diğer verilere SPSS 20.0 programında varyans analizi (ANOVA) ve korelasyon analizi uygulanmış ve ilgili çizelgelerde ortalamalar \% 5 önem düzeyinde Duncan testi kullanılarak karşılaştırılmıştır.

Çizelge 1. Deneme öncesi yetiştirme ortamının bazı fiziksel ve kimyasal özellikleri

\begin{tabular}{llllllllllll}
\hline $\begin{array}{l}\text { Yetiştirme } \\
\text { Ortamı }\end{array}$ & $\mathrm{pH}$ & $\begin{array}{l}\text { Kireç } \\
(\%)\end{array}$ & $\begin{array}{l}\mathrm{EC} \\
(\%)\end{array}$ & Kum (\%) & $\begin{array}{l}\text { Kil } \\
(\%)\end{array}$ & $\begin{array}{l}\text { Silt } \\
(\%)\end{array}$ & $\begin{array}{l}\text { Org. } \\
\text { Mad. } \\
(\%)\end{array}$ & $\begin{array}{l}\mathrm{P}(\mathrm{kg} \\
\mathrm{P} 205 / \mathrm{da})\end{array}$ & $\begin{array}{l}\mathrm{K}(\mathrm{kg} \\
\mathrm{K} 2 \mathrm{~m} / \mathrm{da})\end{array}$ & $\begin{array}{l}\text { Ca } \\
\left(\mathrm{mg} \mathrm{L}^{-1}\right)\end{array}$ & $\begin{array}{l}\text { Bünye } \\
(\%)\end{array}$ \\
\hline Toprak & 8.01 & 22.66 & 0.02 & 60.28 & 7.94 & 31.79 & 1.50 & 4.21 & 36.75 & 6655.67 & 46.00 \\
\hline
\end{tabular}

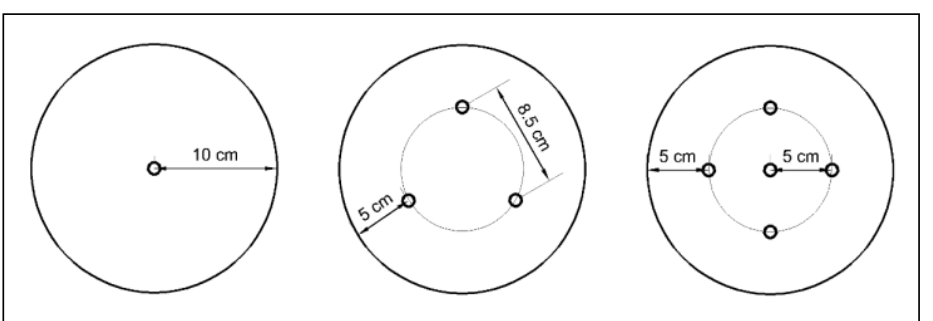

Şekil 1. $R$. carnosula'nın $20 \mathrm{~cm}$ çapındaki saksılara 1'li, 3'lü ve 5'li dikim deseni

\section{BULGULAR VE TARTIŞMA}

\section{Görsel kaliteye bitki yoğunluğunun etkisi}

Üç bitki yoğunluğunda da en yüksek görsel kalite değerleri aynı tarihlerde ve tarih aralıklıklarında belirlenmiştir. 1 bitkili saksılarda $R$. carnosula alan kaplama performansını 3 puan (\%50=alan kaplama iyi) ile en yüksek değer olarak 17 Nisan-1 Mayıs tarihleri arasında 3 hafta boyunca sürdürmüş, çiçeklenme performansını ise 4 puan (\% 75= çiçeklenme çok iyi, kabul edilebilir peyzaj performansı) ile en yüksek değer olarak 1 Mayıs tarihinde göstermiştir. $R$. carnosula'nın bitki yoğunluğuna göre alan kaplama performansının zamana göre değişimi Şekil 2'de, çiçeklenme performansının zamana göre değişimi ise Şekil 3'de görülmektedir.
8 haftalık dönemin ortalamasına göre değerlendirildiğinde en yüksek görsel kalite değerleri, alan kaplama iyi ve çiçeklenme durumu ise orta (kabul edilebilir) olarak 3 bitkili saksılarda belirlenmiştir. Bu sonuca benzer şekilde, XiaoHong ve GuoLiang (2006) saksılarda farklı bitki yoğunluğunun etkisini belirledikleri çalışmalarında, saksı başına 3 bitki olan saksılardaki minyatür güllerde (Rosa hybrida 'Miniature Pink') daha uzun çiçek sürgünü ve daha yüksek yaprak alanı değeri elde etmişlerdir. $R$. carnosula'nın 1 bitkili saksılardaki görsel kalitesi değerlendirildiğinde, alan kaplama ve çiçeklenme performansı orta (kabul edilebilir) olarak tespit edilmiştir. 5 bitkili saksılardaki $R$. carnosula'nın görsel kalitesi değerlendirildiğinde ise, alan kaplama performansı iyi olarak belirlenirken, çiçeklenme performansı çiçeklenme zayıf (kabul edilemez) olarak belirlenmiştir. $R$. carnosula'nın bitki yoğunluğuna göre 8 haftalık alan kaplama performansı ortalaması ve çiçeklenme performansı ortalaması arasındaki farklılıklar istatistiksel açıdan önemli bulunmamıştır. Aynı şekilde, alan kaplama performansı ve çiçeklenme performansı açısından farklı bitki yoğunluğunda elde edilen maksimum değerler arasındaki farklılıklar da istatistiksel açıdan önemli bulunmamıştır (Çizelge 2). 
R. carnosula'nın görsel kalitesi, saksılardaki bitki yoğunluğuna (sayısına) bağlı olarak değişiklikler göstermiştir (Çizelge 2). Bu sonuca benzer şekilde, Contreras ve ark. (2013)'nın çalışmasında, Pennisetum hibritlerinin büyüme formlarına ve renklerine göre değerlendirilen peyzaj performansları, hem saksılı bitkilerde hem de arazideki bitkilerde farklılıklar göstermiştir. Bu sonuca benzer şekilde, Caruso ve ark.
(2010), fesleğen bitkilerinin performansı üzerine 4 farklı bitki yoğunluğunun (saksı başına, 9, 12, 15 ve 18 bitki) etkisini belirledikleri çalışmalarında, saksılardaki bitki yoğunluğuna göre peyzaj performanslarının değişiklik gösterdiğini ve saksı başına 12 bitki olan saksılarda, ağırlık ve yaprak alanı bakımından en iyi sonuçların elde edildiğini belirlemişlerdir.

Çizelge 2. Saksılardaki bitki yoğunluğuna göre 8 hafta için görsel kalitenin alan kaplama ve çiçeklenme performansına göre değerlendirilmesi (1-5 puan)

\begin{tabular}{|c|c|c|c|c|c|c|}
\hline \multirow[t]{2}{*}{ Bitki Yoğunluğu } & \multicolumn{3}{|c|}{ Alanı Kaplama Performansı } & \multicolumn{3}{|c|}{ Çiçeklenme Performansı } \\
\hline & $\begin{array}{l}\text { En yüksek } \\
\text { puan } \\
(1-5)^{x}\end{array}$ & $\begin{array}{l}\text { En yüksek puan alınan } \\
\text { tarih }\end{array}$ & $\begin{array}{l}\text { Ortalama } \\
\text { puan } \\
(1-5)^{y}\end{array}$ & $\begin{array}{l}\text { En yüksek } \\
\text { puan } \\
(1-5)^{\mathrm{x}}\end{array}$ & $\begin{array}{l}\text { En yüksek puan alınan } \\
\text { tarih }\end{array}$ & $\begin{array}{l}\text { Ortalama puan (1- } \\
5)^{y}\end{array}$ \\
\hline \multirow{3}{*}{1 Bitki } & \multirow{3}{*}{3} & 17.04.2018 & & & & \\
\hline & & 24.04 .2018 & $2.13 a^{w}$ & 4 & 01.05 .2018 & $2.75 \mathrm{a}$ \\
\hline & & 01.05 .2018 & & & & \\
\hline \multirow{2}{*}{3 Bitki } & \multirow{2}{*}{5} & 24.04 .2018 & \multirow{2}{*}{$3.13 a$} & \multirow{2}{*}{4} & \multirow{2}{*}{01.05 .2018} & \multirow{2}{*}{$2.50 a$} \\
\hline & & 01.05 .2018 & & & & \\
\hline 5 Bitki & \multirow{2}{*}{4} & 24.04.2018 & \multirow{2}{*}{$2.75 a$} & \multirow{2}{*}{3} & \multirow{2}{*}{24.04 .2018} & \multirow{2}{*}{$2.13 a$} \\
\hline Önomlilik & & 01.05 .2018 & & & & \\
\hline $\begin{array}{c}\text { Önemlilik (P } \\
\text { değerleri) }\end{array}$ & 0.252 & & 0.146 & 0.404 & & 0.231 \\
\hline
\end{tabular}

${ }^{x}$ : Performans derecesinin değerlendirilmesi 1( en düşük kalite) ve 5 (mükemmel kalite) puan arasında yapıldı.

${ }^{\mathrm{y}}$ : Ortalama puan, 8 hafta boyunca her hafta yapılan derecelendirmelerdeki puanların toplanıp ortalamasının alınması ile elde edildi.

w: Sutünlarda Duncan testine göre \% 5 önem düzeyinde farklı ortalamalar ayrı harflerle gösterilmiştir.

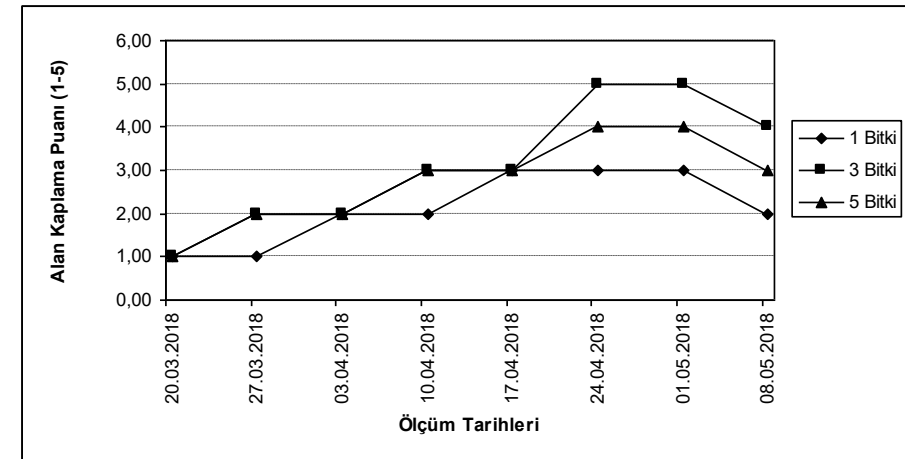

Şekil 2. $R$. carnosula'nın bitki yoğunluğuna göre alan kaplama performansının zamana göre değişimi

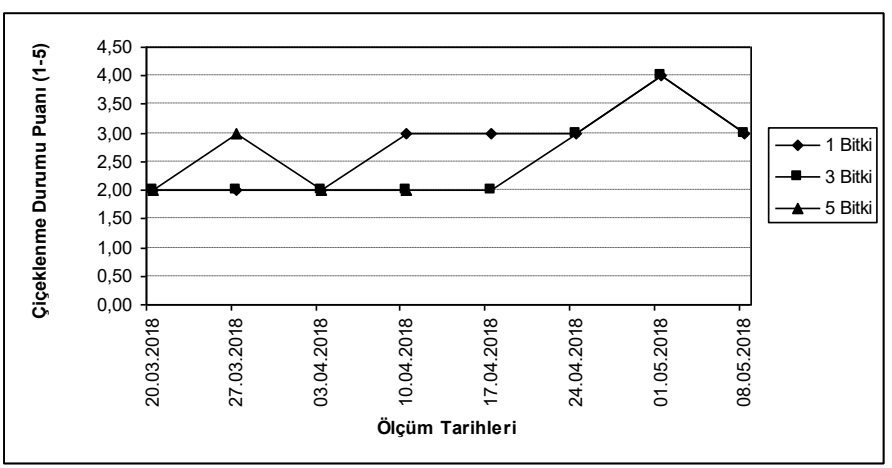

Şekil 3. R. carnosula'nın bitki yoğunluğuna göre çiçeklenme performansının zamana göre değişimi
R. carnosula'nın $20 \mathrm{~cm}$ çapındaki saksılardaki $1^{\prime} l i, 3^{\prime} l u ̈$ ve $5^{\prime}$ li dikim desenine göre deneme süresi içerindeki durumlarından bir görünüm Şekil 4'de sunulmuştur.

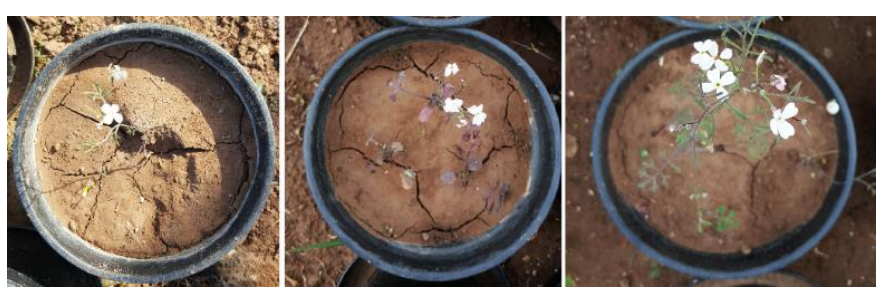

Şekil 4. $R$. carnosula'nın $20 \mathrm{~cm}$ çapındaki saksılardaki 1'li, $3^{\prime} l u ̈$ ve $5^{\prime} l i$ dikim desenine göre deneme süresi içerindeki durumlarından bir görünüm (Orijinal, 2018)

\section{Bitki büyüme özelliklerine bitki yoğunluğunun etkisi}

R. carnosula'nın saksılardaki farklı bitki yoğunluğuna göre büyüme özelliklerine ilişkin ortalamalar Çizelge 3 'de verilmiştir. En uzun bitki boyu $(14.47 \mathrm{~cm})$, en fazla yaprak sayısı (17.15 adet) ve en uzun çiçekli sürgün uzunluğu $(4.64 \mathrm{~cm}) 5$ bitkili saksılarda tespit edilmiştir. En fazla çiçek sayısı ( 3.33 adet) 1 bitkili saksılarda elde edilirken, en fazla çiçekli sürgün sayısı (5.34 adet) ise 3 bitkili saksılarda belirlenmiştir (Çizelge 3 ). 
R. carnosula'nın bitkilerinin bitki boyları değerlerinin bitki yoğunluğuna göre istatistiksel anlamda önemli $(P=0.014)$ farklar içerdiği saptanmıştır (Çizelge 3). Çizelge 2'de görüldüğü gibi bitki yoğunluğuna göre yaprak sayısı değerlerinin istatistiksel anlamda önemli $(P=0.047)$ farklar içerdiği ve çiçekli sürgün sayısı üzerinde bitki yoğunluğunun ( $P=0.004)$ etkisinin istatistiksel anlamda önemli olduğu görülmektedir (Çizelge 3 ). Ancak, çiçek sayısı değerleri arasındaki ve çiçekli sürgün uzunluğu değerleri arasındaki farkların bitki yoğunluğuna göre istatistiksel anlamda önemli olmadığı belirlenmiştir (Çizelge 3).
Bu çalışmada elde edilen saksıdaki bitki yoğunluğunun artması ile çiçek sayısının azalması sonucu, Blanusa ve ark. (2009)'un Petunia hybrida 'Hurrah White'çeşidindeki bulgularıyla benzerlik göstermektedir. Çizelge 2'de görüldüğü gibi saksıdaki bitki sayısı arttıkça bitki boyu uzamıştır, bu sonuç ise Blanusa ve ark. (2009)'nın çalışmasındaki aynı çeşitteki bulgular ile benzerlik göstermemektedir. Bu çalışma sonucunda elde edilen bitki büyüme özellikleri, Kösa ve Uysal (2016)'ın $R$. carnosula'nın doğal populasyonunda belirlediği en yüksek bitki boyu $(27 \mathrm{~cm})$, çiçek sayısı(30 adet) ve çiçek salkım sayısı(16 adet) ile benzerlik göstermezken, yaprak sayısı (18 adet) ile benzerlik göstermektedir.

Çizelge 3. $R$. carnosula'nın büyüme özellikleri üzerine bitki yoğunluğunun etkisi

\begin{tabular}{|c|c|c|c|c|}
\hline \multirow[t]{2}{*}{ Özellik } & \multicolumn{3}{|c|}{ Bitki yoğunluğu (Adet) } & \multirow{2}{*}{$\begin{array}{l}\text { Önemlilik } \\
\text { (P Değerleri) }\end{array}$} \\
\hline & 1 & 3 & 5 & \\
\hline Bitki Boyu (cm) & $10.72 b^{2}$ & $12.61 \mathrm{ab}$ & $14.47 a$ & 0.014 \\
\hline Yaprak Sayısı (Adet) & $12.43 \mathrm{~b}$ & $15.54 a b$ & $17.15 \mathrm{a}$ & 0.047 \\
\hline Çiçek Sayısı (Adet) & $3.33 \mathrm{a}$ & $2.23 \mathrm{a}$ & $1.17 \mathrm{a}$ & 0.115 \\
\hline Çiçekli Sürgün Sayısı (Adet) & $3.22 \mathrm{c}$ & $5.34 \mathrm{a}$ & $4.27 b$ & 0.004 \\
\hline Çiçekli Sürgün Uzunluğu (cm) & $3.73 \mathrm{a}$ & $4.49 \mathrm{a}$ & $4.64 \mathrm{a}$ & 0.156 \\
\hline
\end{tabular}

z: Satırlarda Duncan testine göre \% 5 önem düzeyinde farklı ortalamalar ayrı harflerle gösterilmiştir.

Büyüme özellikleri ile bitki yoğunluğu arasındaki ilişkiler

$R$. carnosula'nın büyüme özellikleri ve bitki yoğunluğu arasındaki ilişkiler Çizelge 4'de verilmiştir. Bitki yoğunluğu ile bitki boyu ve yaprak sayısı arasındaki ilişkiler istatistiksel anlamda önemli ve pozitif yönlü iken, bitki sayısı ile çiçekli sürgün sayısı arasındaki ilişkiler ise istatistiksel anlamda önemli ve negatif yönlü olarak tespit edilmiştir. Ayrıca, bitki boyu ile yaprak sayısı ve yaprak sayısı ile çiçekli sürgün uzunluğu arasında önemli ve pozitif ilişkilerin olduğu belirlenmiştir (Çizelge 4).

Çizelge 4. $R$. carnosula'nın büyüme özellikleri ve bitki yoğunluğu arasındaki ilişkiler

\begin{tabular}{|c|c|c|c|c|c|}
\hline \multirow{2}{*}{ Büyüme Özellikleri* } & \multirow{2}{*}{$\begin{array}{r}\text { Bitki Yoğunluğu } \\
\text { BS }^{* *}\end{array}$} & \multicolumn{4}{|c|}{ Büyüme Özellikleri } \\
\hline & & $\mathrm{BY}^{* *}$ & YS $^{* *}$ & ÇS $^{* *}$ & ÇSS $^{* *}$ \\
\hline \multirow[t]{2}{*}{ BY } & 0.873 & & & & \\
\hline & 0.002 & & & & \\
\hline \multirow[t]{2}{*}{ YS } & 0.786 & 0.797 & & & \\
\hline & 0.012 & 0.01 & & & \\
\hline \multirow[t]{2}{*}{ ÇS } & 0.452 & 0.335 & 0.638 & & \\
\hline & 0.222 & 0.379 & 0.065 & & \\
\hline \multirow[t]{2}{*}{ ÇSS } & -0.717 & -0.461 & -0.648 & -0.541 & \\
\hline & 0.03 & 0.211 & 0.059 & 0.133 & \\
\hline \multirow[t]{2}{*}{ ÇSU } & 0.634 & 0.554 & 0.836 & 0.608 & -0.386 \\
\hline & 0.067 & 0.122 & 0.005 & 0.082 & 0.304 \\
\hline
\end{tabular}

"istatistiksel anlamda önemli olan ilişkiler koyu, P değerleri ise italik yazıımıştır.

**BS: Bitki sayısı(Bitki yoğunluğu), BY: Bitki boyu, YS: Yaprak, ÇS: Çiçek sayısı, ÇSS: Çiçekli sürgün sayısı, ÇSU: Çiçekli sürgün uzunluğu

\section{SONUÇ}

R. carnosula'da saksılardaki bitki yoğunluğuna göre alan kaplama ve çiçeklenme performansları ve büyüme özellikleri değerleri değişmekle birlikte, en iyi peyzaj performansları tüm bitki yoğunluğunda da 24 Nisan ile 1 Mayıs tarihlerinde olmak üzere yaklaşık iki hafta boyunca belirlenmiştir. Bu çalışma, endemik $R$. carnosula türünün, Akdeniz bölgesinde kış mevsimlik çiçeği olarak kullanılma potansiyeli olduğunu, 3 bitkili saksılarda görsel kalite ve 
büyüme özellikleri açısından en iyi peyzaj performasına sahip olduğunu ve saksılı olarak kullanımında 8 hafta boyunca çiçeklenme göstererek etkinliğini 2 ay sürdürebildiğini ortaya koymuştur. Ayrıca bu araştırma, çalışmada sadece bahçe toprağının yetiştirme ortamı olarak kullanılması, deneme boyunca saksılardaki bitkilere besin elementi takviyesi yapılmaması ve yaklaşık olarak haftada bir kez sulama programının uygulanmıs olması ile $R$. carnosula'nın çok fazla bakım gerektirmeden

\section{KAYNAKLAR}

Appel O, Al-Shehbaz IA (2003) Cruciferae. In: The families and genera of vascular plants, Kubitzki K (Ed), pp. 75-174. Springer, Berlin.

Arı E (2010) Cultivation and phytochemical studies on Ricotia carnosula Boiss. \& Heldr. 6th Conference On Medicinal And Aromatic Plants Of Southern European Countries. 18-22 April, 2010, Antalya, Turkey. Pharmacognosy Magazine (Abstract Book of 6. CMAPSEEC), Vol:6, Issue:22 (Suppl.), p: 104.

Arı E, Gürbüz E, Sayın B (2010) Peyzaj sektöründe yer alan bazı aktörlerin doğal bitki kullanımına bakış açılarının Antalya ili örneğinde incelenmesi. IV. Ulusal Süs Bitkileri Kongresi Bildiriler Kitabı: 348-358.

Arı E, Gürbüz E, Tuğrul Ay S (2014) Seed germinations of 20 wild species growing in Antalya, Turkey, with outdoor ornamental plant potential. International Agricultural Symposium - "Agrosym 2014", Jahorina, BOSNA HERSEK, 23-26 Ekim, pp.439-445.

Barman D, Pal P (1999) Effect of nitrogen, potassium and spacing on growth and flowering of chrysanthemum (Chrysanthemum morifolium Ramat.) cv. Chandrama. Horticultural Journal, 12 (1): 51-59.

Belorkar PV, Patil BN, Golliwar VJ, Kothare AJ (1992) Effect of nitrogen levels and spacings on growth, flowering and yield of African marigold (Tagetes erecta L.). Journal of Soils and Crops, 2 (1): 62-64.

Bhati RS, Chitkara SD (1987) Effect of pinching and planting distance on the growth and yield of marigold (Tagetes erecta). Research and Development Reporter, 4 (2): 159-164.

Blanusa T, Vysini E, Cameron RWF (2009) Growth and flowering of Petunia and Impatiens: Effects of competition and reduced water content within a container, Hortscience 44(5):13021307.

Brzuszek RF, Harkess RL, Kelly L (2010) Survey of master gardener use of native plants in the Southeastern United States. HortTechnlogy 20: 462-466.

Burtt BL (1951) The Genus Ricotia. Kew Bulletin. 6(1):123-132.

Caruso G, Melchionna G, Conti S (2010) Effects of plant density on growth and yield of basil grown in gullies by subirrigation. Italus Hortus 17(6):41-44.

Chauhan P, Gupta YC, Dhiman SR, Gupta RK (2014) Effect of planting dates and spacing on growth and floering of African marigold cv. 'Pusa Narangi Gainda'. Annals of Horticulture, 7 (2) :119122.

Coker CE, Knight PR, Anderson JM (2005) Landscape performance of sun coleus in Southern Mississippi. HortTechnology, 15 (3):690-693. dış mekandaki bitkisel tasarımlarda saksılı kullanımının mümkün olduğu sonucunu göstermiştir. $R$. carnosula türü, sahip olduğu ince dokusu, beyaz renkli çiçekleri, küçük boyutları ve dağınık formu ile Akdeniz iklim koşullarına sahip bölgelerdeki bitkisel tasarımlarda kış mevsim çiçeği olarak kullanımı ile bu özelliklere sahip mevsimlik çiçek kullanımındaki eksikliği tamamlamaya yardımcı olacaktır.

Contreras RN, Jim Owen J, Wayne Hanna W, Schwartz B (2013) Evaluation of seven complex Pennisetum hybrids for container and landscape performance in the Pacific Northwestern United States, Horttecnology, 23(4):525-528.

Davis PH (1985) Ricotia L. In: Flora of Turkey and the East Aegean Islands. Vol. 1, Davis PH (Ed), pp. 353-355. Edinburgh Univ. Press, North America.

Dixit SV, Keskar BG (1994) Effect of plant densities and planting time on growth, yield and flowering of Michaelmas daisy. Journal of Maharashtra Agricultural Universities, 19 (3):349-352.

Ferrante A, Trivellini A, Scuderi D, Romano D, Vernieri P (2015) Post-production physiology and handling of ornamental potted plants, Postharvest Biology and Technology, 100:99108

Freyre R, Moseley A, Wilson SB, Knox GW (2012) Breeding and evaluating for landscape performance and fruitlessness in Mexican petunia (Ruellia, Acanthaceae). HortScience, 47 (9):1245-1251.

Gowda JV N, Jayanthi R (1986) Studies on the effect of spacing and season of planting on growth and yield of marigold Tagetes erecta Linn. South Indian Horticulture, 34 (3):198-203.

GuoHua G, TianXiang F, Fu L (2014) Design and optimization of operating parameters for potted anthodium transplant manipulator. Transactions of the Chinese Society of Agricultural Engineering, 30(17):34-42

Heywood V (2003) Conservation and sustainable use of wild species as sources of new ornamentals. Acta Horticulturae 598:43-53.

Jhon AQ, Paul TM, Tanki MI (1991) Effect of nitrogen and plant spacing on growth and flower production of Zinnia elegans Jacq. Advances in Plant Sciences, 4 (1):1-7.

Jhon AQ, Saini SS, Sharma PP (1984) Effect of nitrogen, phosphorus and plant spacing on growth and flowering of pansy (Viola tricolor L.) var. Hiemalis. South Indian Horticulture, 32 (5):292-296.

Karaguzel O, Girmen B (2009) Morphological variations of chaste tree (Vitex agnus-castus L.) genotypes from southern Anatolia. New Zealand Journal of Crop and Horticultural Science 37:253-261.

Khanna K, Arora JS, Singh J (1986) Effect of spacing and pinching on growth and flower production of carnation (Dianthus caryophyllus) cv. Marguerite Scarlet. Indian Journal of Horticulture, 43 (1/2):48-152.

Kobza F (1993) Results of studies on the seed productivity of Tagetes erecta L. and T. patula L. Zahradnictví, 20 (2):103-110.

Kossover O, Frenkel Z, Korol A, Nevo E (2009) Genetic diversity and stress of Ricotia lunaria in "Evolution Canyon", Israel. Journal of Heredity, 100 (4):432-440.

Kösa S, Karagüzel O (2012) Yetiştirme ortamlarının Alnus orientalis fidanlarının büyüme özellikleri ve yaprak besin elementi 
içeriklerine etkileri. Akdeniz Üniversitesi Ziraat Fakültesi Dergisi 25(1):39-46.

Kösa S, Uysal F (2016) Ricotia carnosula'nın Antalya'daki Doğal Populasyonlarında Bazı Morfolojik Özelliklerinin Belirlenmesi Üzerine Bir Çalışma, VI. Süs Bitkileri Kongresi Bildiri Özetleri Kitabı, ss.156.

Mishra HP (1998) Effect of nitrogen and planting density on growth and flowering of gaillardia. Journal of Ornamental Horticulture (New Series), 1 (2):41-47.

Mohanty CR, Behera TK, Samantaray D (1997) Effect of planting time and spacing on growth and flower yield of marigold (Tagetes erecta L.) cv. African Yellow. South Indian Horticulture, 45 $(1 / 2): 41-44$.

Niu G, Rodriguez DS, Aguiniga L (2007) Growth and landscape performance of ten herbaceous species in response to saline water irrigation1. J Environ Hortic., 25(4):204-210.

Owings A, Bracy R, Chen Y, Rosendale R (2010) New liriope and monkey grass groundcover varieties for Louisiana. Louisiana Agriculture, 53 (1):24.

Özüdoğru B, Akaydin G, Erik S, Al-Shehbaz IA, Mummenhoff K (2015) Phylogeny, diversification and biogeographic implications of the eastern Mediterranean endemic genus Ricotia (Brassicaceae). Taxon, 64 (4):727-740.

Özüdoğru B, Erik S, Akaydın G (2008) Türkiye'deki Ricotia (Brassicaceae) türlerinin populasyon yapıları ve yeni yayılış alanları, XXI th National Congress of Biology, June 23-29, İzmirTurkey.

Özüdoğru B, Erik S, Akaydın G (2012) Redescription, distribution and conservation status of cryptic endemic cruciferous species Ricotia tenuifolia Sibth. et Sm., BIORARE-Symposium, 24-27 April, Fethiye, Turkey.

Rani R, Kumar R (1999) Effect of planting time and spacing on growth, flowering and seed yield in balsam (Impatiens balsamina L.). Seed Research, 27 (1):37-40.
Rao DVR, Balasubramanyam SA, Reddy KB, Suryanarayana V (1992) Effect of different spacings and nitrogen levels on growth and flower yield of chrysanthemum (Chrysanthemum indicum L.) cv. Kasturi. South Indian Horticulture , 40 (6): 323-328.

Scheiber SM, Gilman EF, Sandrock DR, Paz M, Wiese C, Brennan M (2008) Postestablishment landscape performance of Florida native and exotic shrubs under irrigated and nonirrigated conditions. HortTechnology 18:59-67.

Selvi P, Paksoy MY (2013) Comparative anatomy of stem and leaf of Ricotia L. growing in Turkey. Bangladesh J. Bot. 42(1):123-130.

ShiZhen C, Jing L, YuanZhi P, QiBing C, BeiBei J, Chong Y (2011) Effects of different plant densities on growth and development of Aconitum carmichaeli. Acta Prataculturae Sinica, 20 (2):278282.

Tyagi AK, Sharma RK, Yadav SK (2006) Effect of nitrogen, phosphorus and plant spacing on growth and flowering of pansy (Viola tricolor L.). Plant Archives, 6 (2):843-844.

Vijayakumar KT, Patil AA, Hulmani NC (1988) Effect of plant density and nitrogen on growth characters and flower yield of China aster (Callistephus chinensis Nees.) cv. Ostrich Plume Mixed. South Indian Horticulture, 36 (6):318-320.

Wilson SB, Knox GW (2009) Landscape performance of green fountain grass alternatives grown in Northern and Southern Florida. HortTechnology, 19(2):471-476.

XiaoHong Y, GuoLiang W (2006) Influence of planting densities and temperature on the growth and post-harvest characters of potted miniature roses (Rosa hybrida 'Miniature Pink'). Journal of Jiangsu Forestry Science \& Technology 33 (2):4-7.

Yamamoto H (2017) Street greening with extended potted plant management by neighbors in the nagono area. Nagoya, Japan. Geographical review of Japan, 90 (2): 86-104. 